Neuropsychology

\section{Computerised neuropsychological testing}

A Collie, P Maruff

\section{Should it be performed by neuropsychologists or team doctors?}

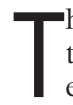
he dual roles of neuropsychological testing in sports concussion are well established. Neuropsychological assessment may aid understanding of the brain structures and processes underlying concussion and the Post Concussion Syndrome. Although this is a primary goal of neuropsychologists working with concussed athletes, a more immediate role lies in facilitating effective post concussion medical management of individual athletes. ${ }^{1}$ Over the past two decades, "paper and pencil" neuropsychological tests have been used to aid concussion management in many sports. ${ }^{2-4}$ However, use of such tests has generally been limited to athletes performing at the elite level. The wide scale use of paper and pencil tests in sports medicine is limited by the requirement that test administration and interpretation be undertaken by trained personnel-for example, neuropsychologists, and that administration is usually on a one-to-one basis. This makes neuropsychological assessment of entire sporting teams time consuming, expensive, and beyond the means of most junior and amateur contact sporting organisations.

These practical limitations, combined with the psychometric limitations of some paper and pencil tests, ${ }^{5}$ have led to the development of a number of computerised neuropsychological test batteries. ${ }^{67}$ These computerised batteries are designed specifically for widespread use in sports medicine, and provide a relatively inexpensive alternative to paper and pencil assessment. Test administration may be accomplished on a large number of athletes over a short period of time, as many athletes may be assessed simultaneously and test administration may be self-guided. If designed appropriately, computerised tests may be both more reliable and more sensitive to the cognitive effects of concussion than paper and pencil tests. ${ }^{5}$ Two questions that arise from the increasing proliferation of computerised neuropsychological assessment in sports concussion are (1) "What role can neuropsychologists play in the administration and interpretation of computerised neuropsychological tests?"; and (2) "Is it appropriate for medical practitioners to independently interpret the results of computerised neuropsychological tests?"

\section{WHAT ROLE CAN \\ NEUROPSYCHOLOGISTS PLAY IN THE ADMINISTRATION AND INTERPRETATION OF COMPUTERISED NEUROPSYCHOLOGICAL TESTS?}

As specialists in brain behaviour relationships, neuropsychologists may offer a level of insight into the athletes' post-concussion cognitive function not available to a non-neuropsychologist. Ideally, a neuropsychologist would administer and interpret the results of every neuropsychological test conducted in sports medicine. One need only investigate the number of athletes involved in contact and collisions sports to realise that this is simply not feasible. For example, the Federation Internationale de Football Association (FIFA) oversees soccer competitions in 186 countries with over 200 million registered participants. In the United States, it is conservatively estimated that 300000 sports related concussions occur every year. ${ }^{8}$ Given the recognised need for baseline assessment in sports concussion, ${ }^{1}$ oneon-one neuropsychological testing of this many athletes is impossible. Computerised assessment requiring minimal or no supervisor assistance with automated reporting of results is the only current available method for completing this daunting task.

This does not mean that neuropsychologists are redundant in sports medicine. The computerised neuropsychological tests currently available were all designed by neuropsychologists who recognised the limitations of paper and pencil assessment in sports concussion. Also, many professional sporting teams hire consultant neuropsychologists as part of their concussion management programmes. An appropriate role for neuropsychologists lies in the assessment of athletes whose post-concussion cognitive impairment, as measured by computerised tests, has not resolved or is of a severe nature. In such instances conventional neuropsychological approaches can help manage the injury and further refine understanding of the injury. Neuropsychologists can also become involved in developing rehabilitation strategies to aid recovery in such athletes.

\section{IS IT APPROPRIATE FOR TEAM DOCTORS TO INDEPENDENTLY INTERPRET THE RESULTS OF COMPUTERISED \\ NEUROPSYCHOLOGICAL TESTS?}

The computerisation of neuropsychological tests has meant that reports detailing the athletes' post-concussion cognitive function are available immediately to the team doctor. We propose that it is appropriate for team doctors to interpret these reports in the absence of a neuropsychologists opinion. This proposal is based on two major conclusions, described below.

The immediate role of neuropsychological assessment in the medical management of athletes is to determine whether a change in cognitive function has occurred from a baseline, or preparticipation, assessment. As the pathophysiological basis of sports concussion remains unknown, ${ }^{9}$ there is no advantage in attempting to determine why cognitive function has changed in an individual athlete. That is, in most cases of concussion, medical management of the athlete is not aided by identifying patterns of spared and impaired cognitive abilities, as per conventional neuropsychological assessment models. Thus, the output from computerised neuropsychological testing is either: (a) "yes, cognitive function has changed after concussion"; or (b) "no, cognitive function has not changed after concussion". This is reflected in the automated reports arising from currently available computerised batteries, at least two of which provide a simple "yes" or "no" result. ${ }^{67}$ We propose that interpretation of such reports does not require neuropsychological expertise. Rather, the medical management challenge lies in incorporating these results with the results of clinical investigations. This leads to our second point, below.

Effective medical management of concussed athletes involves more than neuropsychological assessment. Among other factors, team doctors must consider the athletes' clinical signs and symptoms, the mechanism of injury, the presence or absence of loss of consciousness (LOC) and post-traumatic amnesia (PTA), and the results of other investigations-for example, neuroimaging, when making return-to-play and return-to-training decisions. Medical management also extends beyond return-to-play decisions to include preparticipation examinations, sideline diagnosis and assessment, indications for immediate hospital referral, and exit 
medical examinations. In this context, the team doctor (or another experienced medical practitioner) is the only person with sufficient knowledge and experience to integrate the results of these investigations with the results of neuropsychological assessment and make reasonable decisions.

\section{SUMMARY}

Due to practical constraints, it is unreasonable to suggest that administration and interpretation of computerised neuropsychological tests should always be undertaken by neuropsychologists. Team doctors are well equipped and sufficiently knowledgeable to integrate the results of computerised neuropsychological tests into their athlete medical management procedures. Despite this, neuropsychologists can make significant contribution to sports medicine and athlete medical management.

Br J Sports Med 2003;37:2-3

\section{Authors' affiliations}

A Collie, CogState Ltd, Melbourne, Victoria, Australia and Centre for Sports Medicine Research and Education, The University of Melbourne, Victoria, Australia

P Maruff, Cogsate Ltd, Melbourne, Victoria, Australia and School of Psychological Science, La Trobe University, Bundoora, Victoria,

Australia

Correspondence to: Dr Collie; acollie@cogstate.com

\section{REFERENCES}

1 Aubry M, Cantu R, Dvorak J, et al. Summary and agreement statement of the first International Conference on Concussion in Sport, Vienna 2001. Brit J Sport Med 2002;36:6-10

2 Butler R. Neuropsychological investigation of amateur boxers. Brit J Sport Med 1994;28: 187-90.
3 Maddocks D, Saling M. Neuropsychological deficits following concussion. Brain Injury 1996;10:99-103.

4 Matser JT, Kessels AG, Jordan BD, et al. Chronic traumatic brain injury in professional soccer players. Neurology 1998;51:791-6.

5 Collie A, Darby DG, Maruff P. Computerised cognitive assessment of athletes with sports related head injury. Brit J Sport Med 2001;35:297-302

6 Erlanger D, Saliba E, Barth JT, et al. Monitoring resolution of post-concussion symptoms in athletes: Preliminary results of a Web-based neuropsychological test protocol. J Athletic Train 2001;36:280-7.

7 Makdissi M, Collie A, Maruff P, et al. Computerized cognitive assessment of concussed Australian rules footballers. Brit J Sport Med 2001;35:354-60.

8 Thurman DJ, Branche CM, Sniezek JE. The epidemiology of sports-related traumatic brain injuries in the United States: recent developments. J Head Trauma Rehab 1998;13:1-8.

9 McCrory P, Johnston K, Mohtadi NG, et al. Evidence-based review of sports-related concussion: Basic Science. Clin J Sport Med $2001 ; 11: 160-5$

\section{BASEM}

\section{John Clegg}

B $y$ an unfortunate coincidence, all the executive posts in the British Association of Sports and Exercise Medicine (BASEM) expired at the 2002 AGM and led to retirement of most of the old guard. Since 1992 all the donkey work for the Association had been performed by John Clegg, a retired dentist, who since then had thrown himself into the role of Honorary Secretary of the Association.

Following schooling in Bolton he had graduated from Liverpool University in Dentistry in 1959 and spent some time in the Facio-Maxillary Unit at Broadgreen Hospital before entering General practice in St Helens. Sport had always been a major part of his life and as well as playing golf, cricket, and rugby union adequately, he was good enough at tennis to have played Tony Pickard in the Semi-Finals of the Lancashire Junior Championships. In the red hot rugby league town of St Helens he switched codes as a spectator, then became the club dentist and wrote the first published paper on mouth protection in rugby some forty years ago.

His involvement with St Helens grew to such an extent that in the early 1980s he became Chairman of the Club for three years, leading them to Wembley successes and being instrumental in bringing no less a player than Mal Meninga to the Club. For many, retirement in their late $40 \mathrm{~s}$ as a result of a chronic back problem, would have been the signal to slow down. John however went on one of the BASEM General Courses at Loughborough in 1977 and joined the Association. He was co-opted onto the Executive to organise the 1991 Congress at Windermere, and did so with such success that following a relatively bloodless coup he became the Honorary Secretary soon after. Since that day, quite voluntarily, he has given up at least a day per week to ensure that the Association runs smoothly, and took the Congress back to the Low Wood Hotel in 2002 for his swan song and one of the most academically enlightening congresses that the Association has seen.

To make sure that he was up to the job he obtained an Economics Degree from the Open University five years ago in and has mixed his BASEM tasks with a seat on the Bench in St Helens since 1974, Chairing the Governers of Cowley High School in St Helens for the past eight years, Chairing the St

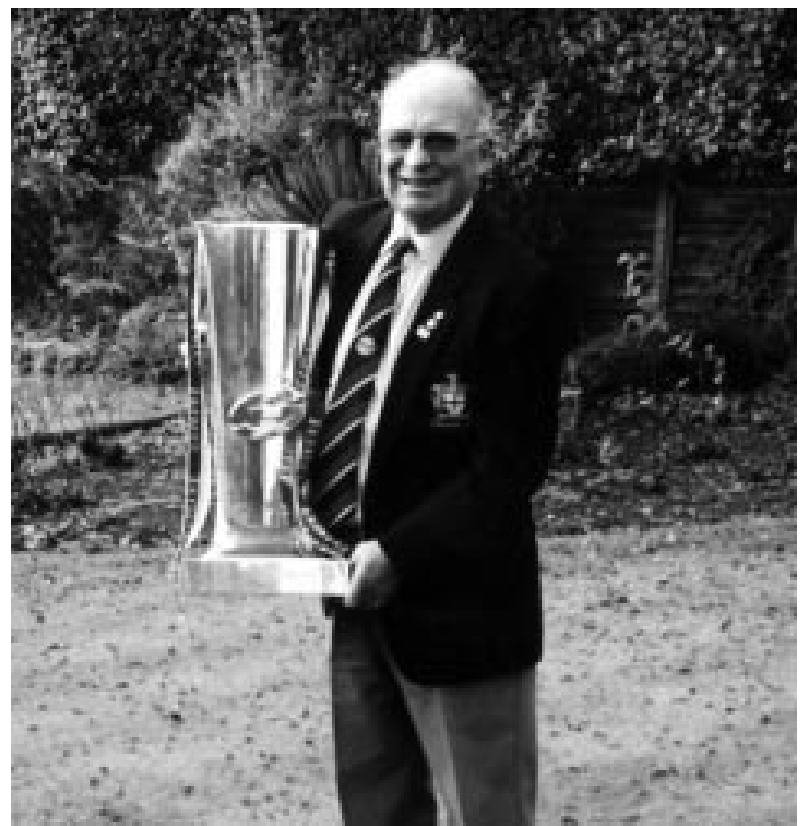

John Clegg holding Rugby League Super League Grand Final Trophy won by St Helens at Old Trafford in October 2002.

Helens Round Tablers and now acting as the North West representative on the National Council of the 41 Club.

For all his voluntary work it was most fitting that BASEM made him a Life Member at the 2002 AGM, and lucky is any organisation that now gains his massive administrative skills. It says much for the man that in order to replace him BASEM is looking to open a staffed office. The Executive is poorer still for the loss of Donald MacLeod and Harry Thomason, both of whom have a long record of service for the Association, and whose expertise will be sorely missed.

P Milroy Secretary, BASEM 